\section{The National Diabetic Retinopathy Laser Treatment Audit. I. Maculopathy}

C.C. BAILEY, J.M. SPARROW,

R.H.B. GREY, H. CHENG

\section{Abstract}

The National Diabetic Retinopathy Laser Treatment Audit is a prospective survey of laser treatment for diabetic retinopathy throughout the United Kingdom. This paper describes the methodology of the study and presents data on 546 patients who were undergoing their first photocoagulation treatment for diabetic maculopathy (without proliferative retinopathy) during a 2 month period in 1995. Validation of the level of participation, patient demographic features, sources of referral, the level of systematic screening and waiting times are described. Maculopathy was detected as a result of systematic screening in $65.2 \%$, whilst $12.3 \%$ of cases presented symptomatically. The percentage of cases treated within 8 weeks of listing was $83.1 \%$, whilst $7 \%$ waited for more than 12 weeks for their laser treatment. The retinopathy features and the type of treatment given are also described. The maculopathy was said to be predominantly exudative in nature in $69.8 \%$ of cases, and $96.2 \%$ of these eyes were treated with focal macular laser. The maculopathy was said to be diffusely oedematous in nature in $8.6 \%$ of cases, and $78.7 \%$ of these eyes were treated with grid macular laser.

Key words Diabetic retinopathy, Laser, Photocoagulation, Maculopathy, Screening, Process

The management of diabetic retinopathy represents a significant workload for the ophthalmic services. It is estimated that there are almost 1.4 million adults with diabetes in the United Kingdom, ${ }^{1}$ and maculopathy is a major cause of visual impairment in diabetic patients. ${ }^{2}$ In the Wisconsin Epidemiologic Study of Diabetic Retinopathy macular oedema was present in about $11 \%$ of the population with younger-onset diabetes, and in $8.4 \%$ of the older-onset group, ${ }^{3}$ whilst Sparrow et al. ${ }^{4}$ found that the prevalence of sight-threatening maculopathy was $10 \%$ in a population of non- insulin-treated diabetics in an English town. Whilst proliferative retinopathy may lead to a greater level of blindness, maculopathy is numerically a greater problem.

Diabetic maculopathy may be classified into exudative, oedematous or ischaemic types, ${ }^{5}$ although for many eyes there may be an overlap between these categories. Alternatively, maculopathy may be described as focal, diffuse or ischaemic in nature. Within this definition, focal maculopathy includes both focal exudates and focal/multifocal oedema. In focal maculopathy, clusters of microaneurysms are usually found within areas of focal retinal oedema, and are a major source of leakage. ${ }^{6}$ In the diffuse variety, there is a generalised breakdown of the inner blood-retina barrier in which there is also a diffuse leakage from retinal capillaries and arterioles. ${ }^{7,8}$ Several studies have shown a benefit from photocoagulation treatment for diabetic maculopathy, ${ }^{9-12}$ including the ETDRS which showed a benefit from laser treatment for eyes with 'clinically significant macular oedema.' ${ }^{13,14}$

Despite the availability of an effective treatment, many patients do still go blind from diabetic maculopathy., ${ }^{2,15}$ The Saint Vincent Declaration set as one of its targets reducing the incidence of blindness due to diabetes by onethird or more. ${ }^{16}$ Whether this can be achieved depends on a number of factors: (i) a reduction in the incidence of sight-threatening retinopathy from improved glycaemic control; ${ }^{17}$ (ii) earlier detection of retinopathy, related to the provision of screening; and (iii) timely and appropriate treatment of diabetic retinopathy.

This paper reports an audit that was designed to study the processes of delivery of photocoagulation treatment for diabetic retinopathy throughout the UK. It examines the sources of referral, the mode of detection of retinopathy, numbers of patients treated, and the severity of retinopathy at the time of the first laser treatment. It also assesses the mode of treatment given, as well as the grade of ophthalmologist performing the treatment.
C.C. Bailey J.M. Sparrow R.H.B. Grey

H. Cheng The Royal College of Ophthalmologists 17 Cornwall Terrace London NW1 4QW, UK

The Department of Health provided funding for this project. 


\section{Method}

A preliminary questionnaire was sent to all consultant ophthalmologists in the UK to ascertain whether they performed laser treatment for diabetic retinopathy and the pattern of referral for those consultants who did not undertake such treatment. All consultant

ophthalmologists who treated diabetic retinopathy were then invited to participate in this audit. Inclusion criteria for patient entry into the audit were: (i) patients with diabetic maculopathy, in the absence of proliferative retinopathy, who were having their first laser treatment in either eye; (ii) patients with proliferative retinopathy who were having their first panretinal photocoagulation in a particular eye. Recruitment into the audit was during June and July 1995.

The ophthalmologist performing the laser treatment completed a questionnaire for all included patients recording the retinopathy features, the source of referral, the mode of detection of the retinopathy, waiting times, best-recorded visual acuity, the amount and type of treatment given, and the grade of ophthalmologist performing the treatment. The patient's hospital number was recorded to allow follow-up to take place, but to maintain confidentiality the name of the patient was not requested.

All the data were returned to the Royal College of Ophthalmologists and stored in accordance with the Data Protection Act. The data were double-entered, stored on a computerised database, and analysed using a commercially available statistical software package (SPSS for Windows 6.0). Where both eyes were given laser treatment for maculopathy at the same session, the right eye was included in the analysis (there was no significant difference in results between including the right or left eyes in the analysis).

\section{Validation of the sample}

To assess the level of participation in this audit, approximately $10 \%$ of all the ophthalmic units in the UK were randomly chosen for a visit to ascertain the level of participation. The consultant ophthalmologists, and the clinical audit managers for these ophthalmic units, were sent a letter requesting permission. A visit was then arranged wherein the notes of all diabetic patients given laser treatment during the audit period were reviewed, to determine the proportion wrongly excluded.

Information collected included the age and gender of the patient, the type of retinopathy present, and the date of the laser treatment. This would allow a comparison between the patients entered into the audit and those eligible subjects inappropriately excluded.

\section{Results}

\section{Initial questionnaire}

The initial questionnaire was sent to 641 consultant ophthalmologists in the UK in April 1995. There was an $89.6 \%$ response to this questionnaire and $79.4 \%$ of the respondents said that they undertook laser treatment for diabetic retinopathy (Table 1 ); $4.7 \%$ of consultants said that they undertook laser treatment for diabetic retinopathy but also referred some patients for laser treatment. For consultants who did not undertake laser treatment for diabetic retinopathy their referral was to a consultant ophthalmologist outside their provider unit in only $1.6 \%$. A total of $10.2 \%$ of the consultant ophthalmologists performed laser treatment for their patients without the help of other grades of staff. Only one consultant ophthalmologist stated that he did not wish to participate in this audit.

Eight hundred and thirty patients were recruited into the audit. Of these, 546 (65.8\%) were undergoing first laser treatment for maculopathy (in the absence of proliferative retinopathy) in either eye, and are the subject of this paper. The remaining $34.2 \%$ were undergoing their first panretinal photocoagulation in the affected eye, and will be discussed in a subsequent publication. $58.6 \%$ of patients were recruited during June 1995. Questionnaires were returned from $80.1 \%(n=137)$ of all possible ophthalmic units. In eight ophthalmic units none of the consultant ophthalmologists undertook laser treatment for diabetic retinopathy. Of the units that did undertake laser treatment for diabetic retinopathy from which no responses were obtained $(n=34), 24$ (70.6\%) were units with two or fewer consultants, 5 $(14.7 \%)$ were units with three consultants, and 5 (14.7\%) were units with four consultants.

Table 1. The delivery of photocoagulation treatment for diabetic retinopathy throughout the United Kingdom

\begin{tabular}{lccc}
\hline & $n$ & $\begin{array}{c}\text { Percentage of responders } \\
(n=574)\end{array}$ & $\begin{array}{c}\text { Percentage of all consultant ophthalmologists } \\
(n=641)\end{array}$ \\
\hline $\begin{array}{l}\text { Consultant undertakes laser treatment for } \\
\text { patients with diabetic retinopathy }\end{array}$ & 456 & 79.4 & 71.1 \\
$\begin{array}{l}\text { Consultant refers diabetic patients for laser } \\
\text { treatment }\end{array}$ & 51 & 8.9 \\
$\begin{array}{l}\text { Consultant does not have patients with diabetic } \\
\text { retinopathy under his/her care }\end{array}$ & 67 & 11.7 \\
\begin{tabular}{l} 
Non-responders to initial questionnaire \\
\hline
\end{tabular} & 67 & & 7.9 \\
\hline
\end{tabular}

Data are from the pre-audit survey of all UK consultant ophthalmologists. 


\begin{tabular}{|c|c|c|c|c|c|}
\hline Ophthalmic unit & $\begin{array}{l}\text { Hospital records for } \\
\text { assessment }\end{array}$ & $\begin{array}{l}\text { Hospital records } \\
\text { unavailable for } \\
\text { assessment }\end{array}$ & $\begin{array}{l}\text { Patients included in } \\
\text { the audit }\end{array}$ & $\begin{array}{l}\text { Eligible patients } \\
\text { missed from the audit }\end{array}$ & $\begin{array}{l}\text { Unit size (no. of } \\
\text { consultant } \\
\text { ophthalmologists) }\end{array}$ \\
\hline Unit 1 & 55 & 6 & 2 & 5 & 3 \\
\hline Unit 2 & 35 & 3 & 9 & 1 & 3 \\
\hline Unit 3 & 27 & 2 & 1 & 1 & 2 \\
\hline Unit 4 & 34 & 11 & 2 & 1 & 2 \\
\hline Unit 5 & 63 & 3 & 14 & 0 & 2 \\
\hline Unit 6 & 51 & 1 & 10 & 1 & 3 \\
\hline Unit 7 & 76 & 2 & 1 & 2 & 2 \\
\hline Unit 8 & 20 & 2 & 4 & 3 & 3 \\
\hline Unit 9 & 86 & 24 & 5 & 1 & 4 \\
\hline Unit 10 & 63 & 18 & 7 & 2 & 4 \\
\hline Unit 11 & 32 & 8 & 5 & 3 & 5 \\
\hline Unit 12 & 86 & 5 & 0 & 7 & 4 \\
\hline Unit 13 & 50 & 15 & 5 & 0 & 3 \\
\hline Unit 14 & 40 & 5 & 20 & 0 & 4 \\
\hline Unit 15 & 56 & 9 & 7 & 3 & 3 \\
\hline Unit $16^{\mathrm{a}}$ & 0 & 0 & 0 & 0 & 1 \\
\hline Total & 774 & $114(14.7 \%)$ & $\begin{array}{l}92(75.4 \% \text { of all } \\
\text { eligible patients) }\end{array}$ & $\begin{array}{l}30 \text { ( } 24.6 \% \text { of all } \\
\text { eligible patients) }\end{array}$ & \\
\hline
\end{tabular}

${ }^{\mathrm{a}}$ This unit had one consultant ophthalmologist, who did not undertake laser treatment for diabetic retinopathy.

\section{Validation of the sample}

Seventeen ophthalmic units $(9.5 \%$ of the number of ophthalmic units in the UK) were contacted concerning the validation exercise. One unit declined to participate. The size of the units chosen for the validation exercise was representative of that for the UK as a whole. The levels of participation for these units are shown in Table 2. Overall, for the hospital records examined, $75.4 \%$ of all eligible patients were included in the audit. Relevant hospital records were not available for assessment in $14.7 \%$ of cases. Table 3 shows the comparison between the patients included and those inappropriately missed from the audit. There was no significant difference between the missed and correctly included groups with respect to the type of retinopathy, age and gender. During June 1995, 79.5\% of eligible patients were correctly included, and during July 1995 $69.4 \%$ of eligible patients were correctly included, giving an overall inclusion rate of $75.4 \%$.

\section{Explanation given to the patient and consent for treatment}

A written explanation about possible side-effects was given to only $3.7 \%$ of patients, whilst $90.8 \%$ were given a verbal explanation alone. It was stated that a consent form for treatment was not signed by the patient in $29.7 \%$ of cases.

\section{Patient characteristics}

The mean age of the patients was 62.2 years (range 21-94 years), of whom $48.2 \%$ were female and $51.8 \%$ were male. The right eye was undergoing treatment in $35 \%$ of cases, the left eye in $39.5 \%$, whilst both eyes were being treated in the first session in $25.5 \%$.

Diabetes mellitus was diagnosed before the age of 30 years and required insulin treatment (younger-onset group) in $8.4 \%$ (36), but was diagnosed after the age of 30 years (older-onset) in $91.6 \%$ (392) of cases. For the olderonset group, 143 (36.6\%) required insulin, 229 (58.6\%) were on oral hypoglycaemic agents, whilst $19(4.8 \%)$ were on diet alone. The mean duration of diagnosed diabetes for all of these patients with maculopathy was 13.2 years ( $0-68.4$ years), being 25 years (10-68.4 years) for the younger-onset group and 12.1 years ( $0-57.4$ years) for the older-onset group.

\section{Source of referral}

The sources of referral to the ophthalmology clinic are shown in Table 4 . A total of $75.2 \%$ of patients were referred by their hospital physician or general practitioner. In $10.9 \%$ of cases the referral was initiated by the optometrist. The maculopathy requiring laser treatment was present at the first ophthalmology outpatient visit in $58.9 \%$ (322) of cases, and for these cases (excluding self-referrals) the maculopathy was correctly identified by the referrer in $80.8 \%$ (236) of cases.

Table 3. Validation of the sample: a comparison between those included and those inappropriately missed from inclusion in the audit

\begin{tabular}{llll}
\hline & Included in audit $(n=92)$ & Missed from audit $(n=30)$ & All eligible patients $(n=122)$ \\
\hline Age (years) & $\begin{array}{l}\text { Mean 59.6 } \\
\text { (range 21-94) }\end{array}$ & $\begin{array}{l}\text { Mean 61.9 } \\
\text { (range 17-82) }\end{array}$ & $\begin{array}{l}\text { Mean 60.2 } \\
\text { (range 17-94) }\end{array}$ \\
$\begin{array}{l}\text { Gender } \\
\text { Type of retinopathy } 46.7 \%, \text { female 53.3\% }\end{array}$ & $\begin{array}{l}\text { Maculopathy 69.6\%, proliferative } \\
\text { retinopathy 30.4\% }\end{array}$ & $\begin{array}{l}\text { Maculopathy 70\%, proliferative } \\
\text { retinopathy 30\% }\end{array}$ & $\begin{array}{l}\text { Maculopathy 69.7\%, proliferative } \\
\text { retinopathy 30.3\% }\end{array}$ \\
\hline
\end{tabular}


Table 4. Sources of referral to the ophthalmology clinic

\begin{tabular}{lrc}
\hline Source of referral & $n$ & $\%$ \\
\hline Hospital physician & 212 & 39.3 \\
General practitioner & 194 & 35.9 \\
Optometrist & 59 & 10.9 \\
Hospital ophthalmologist & 62 & 11.5 \\
Ophthalmic medical practitioner & 7 & 1.3 \\
Self-referral & 6 & 1.1 \\
Total & 540 & 100 \\
\hline
\end{tabular}

\section{Level of systematic screening}

The mode of detection of the retinopathy for the whole group is presented in Fig. 1. For the group in whom the maculopathy requiring laser treatment was present at the first ophthalmology outpatient visit, detection was the result of systematic screening in $64.8 \%$ (206), as a chance finding in $18.9 \%$ (60), whilst $13.5 \%$ (43) of patients presented symptomatically. In this context, systematic screening was defined as at least annual, planned, dilated fundal examination by an optometrist or doctor.

Waiting times to be seen in the outpatient clinic and for the laser treatment

Table 5 presents the waiting times to be seen in the ophthalmology clinic and for the laser treatment. The median waiting time from listing until the laser treatment was 4 weeks (range $0-56$ weeks), 19.3\% being treated on the same day, $62.1 \%$ within 4 weeks, whilst $7 \%$ waited for more than 12 weeks for their laser treatment. For those patients in whom the maculopathy requiring laser treatment was present at the first ophthalmology outpatient clinic, the median waiting time from referral to the first appointment was 7 weeks (range 0-52 weeks). In all, $35.2 \%$ were seen within 4 weeks of referral, whilst $9.4 \%$ waited for more than 12 weeks for their clinic appointment. For this group, the median overall wait from the time of referral to the time of laser treatment was 10 weeks (range $0-60$ weeks), with $35.8 \%$ waiting for more than 12 weeks from the time of referral.

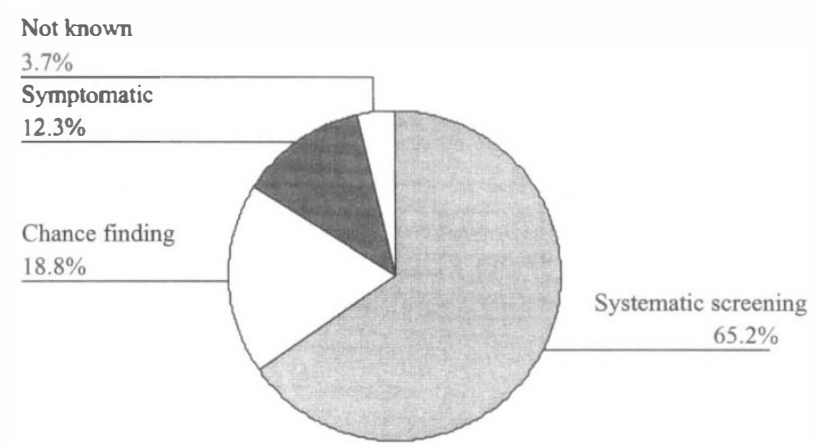

Fig. 1. Mode of detection of retinopathy that led to referral to the ophthalmology outpatient clinic. In this context, systematic screening refers to the detection of retinopathy as a result of at least annual, planned, dilated fundal examination by an optometrist or doctor. A chance finding refers to the detection of the pathology in a patient who did not undergo systematic screening as defined above, and who did not present symptomatically.
Table 5. Waiting times to be seen in the ophthalmology clinic and for the laser treatment

\begin{tabular}{lccc}
\hline Wait (weeks) & $n$ & $\%$ & Cumulative \% \\
\hline For laser treatment & & & \\
Treatment on same day & 102 & 19.3 & 19.3 \\
$1-4$ & 226 & 42.8 & 62.1 \\
$5-8$ & 111 & 21 & 83.1 \\
$9-12$ & 52 & 9.9 & 93 \\
$13-16$ & 19 & 3.6 & 96.6 \\
$>16$ & 18 & 3.4 & 100 \\
Total & 528 & 100 &
\end{tabular}

For clinic appointment ${ }^{\mathrm{a}}$

$\begin{array}{lrcc}\text { Up to } 4 & 101 & 35.2 & 35.2 \\ 5-8 & 92 & 32 & 67.2 \\ 9-12 & 67 & 23.4 & 90.6 \\ 13-16 & 16 & 5.6 & 96.2 \\ >16 & 11 & 3.8 & 100 \\ \text { Total } & 287 & 100 & \end{array}$

Overall $^{\mathrm{b}}$

\begin{tabular}{lrcc} 
Up to 4 & 43 & 15.4 & 15.4 \\
$5-8$ & 66 & 23.7 & 39.1 \\
$8-12$ & 70 & 25.1 & 64.2 \\
$13-16$ & 51 & 18.2 & 82.4 \\
$>16$ & 49 & 17.6 & 100 \\
Total & 279 & 100 & \\
\hline
\end{tabular}

${ }^{a}$ Refers to cases where maculopathy requiring treatment was present at the first ophthalmology outpatient visit.

${ }^{b}$ Refers to the overall wait from the time of referral to the time of the laser treatment for those cases where maculopathy requiring treatment was present at the first ophthalmology outpatient visit.

\section{Retinopathy features}

The maculopathy was described as predominantly exudative in $69.8 \%$ (381), oedematous in $22.3 \%$ (122) and ischaemic in $2.6 \%$ (14) of cases. In $5.3 \%$ of cases, no distinction could be made as to whether exudates or oedema predominated. Where the maculopathy was predominantly oedematous, this was described as focal/ multifocal in nature in 72 cases $(59.0 \%)$ and diffuse in 47 cases $(38.5 \%)$. Overall, $8.6 \%$ of all the maculopathy was described as diffuse, $87.4 \%$ as focal, $2.6 \%$ as ischaemic, and as indeterminate in $1.4 \%$ of cases. Where the maculopathy was predominantly exudative in nature, the exudates were more than one disc diameter from the centre of the macula in $19.4 \%$ of cases. Where the oedema was focal/multifocal in nature, this was more than 1 disc diameter from the centre of the macula in $15.3 \%$ of cases.

\section{Visual acuity in the eye prior to macular laser treatment}

The best-recorded visual acuity in the eye to be treated is shown in Table 6 , which reveals that $56.2 \%$ had visual acuity of $6 / 9$ or better, whilst $16.1 \%$ had a visual acuity of $6 / 24$ or worse. Where the visual acuity was $6 / 9$ or worse, $25.8 \%$ of cases were said to have some degree of cataract sufficient to cause a reduction in visual acuity. Overall, $6.1 \%$ of the patients had undergone a Hospital Eye Service refraction in the preceding 6 months. Where the best-recorded visual acuity was worse than $6 / 9$ in the 
Table 6. The best-recorded visual acuity in the eye prior to treatment

\begin{tabular}{lrrrrr}
\hline & $\begin{array}{c}\text { Visual acuity in the } \\
\text { eye to be treated }\end{array}$ & & \multicolumn{2}{c}{$\begin{array}{c}\text { Visual acuity in the } \\
\text { better eye }\end{array}$} \\
\cline { 2 - 3 } Visual acuity & \multicolumn{1}{c}{$n$} & $\%$ & & $n$ & $\%$ \\
\hline $6 / 5$ & 54 & 9.9 & & 84 & 15.4 \\
$6 / 6$ & 119 & 21.8 & & 161 & 29.5 \\
$6 / 9$ & 134 & 24.5 & & 149 & 27.3 \\
$6 / 12$ & 87 & 15.9 & & 83 & 15.2 \\
$6 / 18$ & 62 & 11.4 & & 37 & 6.8 \\
$6 / 24$ & 40 & 7.3 & & 19 & 3.5 \\
$6 / 36$ & 31 & 5.7 & & 9 & 1.6 \\
$6 / 60$ & 9 & 1.6 & & 2 & 0.4 \\
$<6 / 60$ & 8 & 1.5 & & 1 & 0.2 \\
Missing & 2 & 0.4 & & 1 & 0.2 \\
Total & 546 & 100 & & 546 & 100 \\
\hline
\end{tabular}

eye to be treated, this was taken unaided in $13.4 \%$, using spectacles in $39.5 \%$, with pinhole in $24.4 \%$ and using both spectacles and pinhole in $22.7 \%$. Where spectacles were worn $(n=255)$, only in $11.8 \%$ (30) of cases were they known to have been prescribed in the 3 months prior to the laser treatment, and in $46.7 \%$ (119) the spectacles were more than 3 months old. In $41.5 \%$ (106) the age of the spectacles was not known.

Multiple regression analysis demonstrated that a better visual acuity at baseline was significantly related $(p<0.01)$ to lower age, the presence of focal (vs diffuse) maculopathy, exudative (vs oedematous) maculopathy, and the detection of maculopathy by systematic screening. For those patients with visual acuity of $6 / 6$ or better, $85 \%$ had predominantly exudative and $9.2 \%$ had predominantly oedematous maculopathy whilst for the patients with visual acuity of worse than $6 / 6,62.6 \%$ had exudative maculopathy and $28.5 \%$ had oedematous maculopathy. The type or duration of diabetes and the waiting time for laser treatment were not found to be related to the visual acuity at baseline, but the waiting time to be seen in the clinic for those patients whose maculopathy was present at the first ophthalmology outpatient visit was significantly longer $(p<0.001)$ for those patients with visual acuity of $6 / 6$ or better than those with worse visual acuity (median 8 and 6 weeks respectively).

\section{Grade of ophthalmologist performing macular laser treatment}

The grade of ophthalmologist performing the macular laser treatment is shown in Table 7. Consultant ophthalmologists performed $42.9 \%$ of the treatment.

\section{Treatment given}

Four patients from two centres were given treatment using a diode laser. For the other cases, argon laser photocoagulation was used.

\section{Focal treatment}

For those eyes given focal treatment, the mean numbers of burns used was 69.3 ( $n=452$, range $4-650)$. The most frequently used spot sizes for each treatment are shown in
Table 7. Grade of ophthalmologist performing macular laser treatment

\begin{tabular}{lrr}
\hline Grade & $n$ & $\%$ \\
\hline Consultant & 225 & 42.9 \\
Associate specialist & 79 & 15.1 \\
Staff grade & 54 & 10.3 \\
Clinical assistant & 53 & 10.1 \\
Fellow & 6 & 1.1 \\
Senior registrar & 28 & 5.3 \\
Registrar & 64 & 12.2 \\
SHO & 5 & 1.0 \\
SHO or other under supervision & 10 & 2.0 \\
Total & 524 & 100 \\
\hline
\end{tabular}

Table 8. One hundred micrometres was the most frequently used spot size in $52.2 \%$ of cases, whilst $200 \mu \mathrm{m}$ was the most frequently used spot size in $25.4 \%$ of cases.

\section{Grid treatment}

For those eyes given grid laser treatment, the mean number of burns was $161.6(n=91$, range $14-1226)$. A spot size of $100 \mu \mathrm{m}$ was used in $58.2 \%$ of cases, whilst a spot size of $200 \mu \mathrm{m}$ was used in $26.4 \%$ of cases.

The treatment given for eyes with different types of maculopathy is shown in Table 9. For eyes with exudative maculopathy, $94.8 \%$ were given focal treatment. For eyes with oedematous maculopathy, $47.5 \%$ were given grid treatment. For those eyes with diffuse oedematous maculopathy, $76.6 \%$ were given grid treatment. Overall, for those eyes with focal maculopathy (exudative or focal/multifocal oedematous maculopathy) $90.2 \%$ were given focal treatment, $7.7 \%$ were given grid treatment and $2.1 \%$ were given a combination of focal and grid treatment.

\section{Follow-up}

$6.3 \%$ of cases were to be seen again specifically for further treatment. For the group in which the next follow-up appointment was for reassessment rather than specifically for further treatment, the times until the next planned clinic review are shown in Table 10. Review was

Table 8. The most frequently used laser spot size for the maculopathy treatment

\begin{tabular}{lrrrrc}
\hline & \multicolumn{2}{c}{ Focal treatment } & & \multicolumn{2}{c}{ Grid treatment } \\
\cline { 2 - 3 } \cline { 5 - 6 } Spot size $(\mu \mathrm{m})$ & \multicolumn{1}{c}{$n$} & $\%$ & & $n$ & $\%$ \\
\hline 50 & 71 & 15.8 & & 6 & 6.6 \\
75 & 2 & 0.4 & & 0 & 0 \\
100 & 236 & 52.2 & & 53 & 58.2 \\
120 & 4 & 0.9 & & 0 & 0 \\
125 & 2 & 0.4 & & 1 & 1.1 \\
128 & 1 & 0.2 & & 0 & 0 \\
150 & 15 & 3.3 & & 5 & 5.5 \\
200 & 115 & 25.4 & & 24 & 26.4 \\
250 & 2 & 0.4 & & 1 & 1.1 \\
300 & 2 & 0.4 & & 0 & 0 \\
500 & 2 & 0.4 & & 1 & 1.1 \\
Total & 452 & 100 & & 91 & 100 \\
\hline
\end{tabular}


Table 9. Type of macular laser treatment given

\begin{tabular}{|c|c|c|c|c|c|c|}
\hline \multirow[b]{2}{*}{ Type of treatment } & \multicolumn{2}{|c|}{ Exudative maculopathy } & \multicolumn{2}{|c|}{ Oedematous maculopathy } & \multicolumn{2}{|c|}{ Diffuse oedematous maculopathy } \\
\hline & $n$ & $\%$ & $n$ & $\%$ & $n$ & $\%$ \\
\hline Focal & 350 & 94.8 & 57 & 48.3 & 10 & 21.3 \\
\hline Grid & 14 & 3.8 & 56 & 47.5 & 36 & 76.6 \\
\hline Focal and grid & 5 & 1.4 & 5 & 4.2 & 1 & 2.1 \\
\hline Total & 369 & 100 & 118 & 100 & 47 & 100 \\
\hline
\end{tabular}

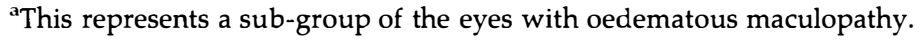

to be within 4 weeks in $8.7 \%$, whilst $19.3 \%$ were to wait more than 12 weeks before reassessment. The median planned follow-up was 12 weeks (range 1-40 weeks).

\section{Fluorescein angiography}

Fluorescein angiography was performed prior to treatment in $19.5 \%$ (106) of cases overall: in $14 \%$ (54) of the group with exudative maculopathy, in $34 \%$ (16) of the group with diffuse oedematous maculopathy, and in $28.6 \%$ (4) in the category with ischaemic maculopathy.

\section{Discussion}

Eight hundred and thirty patients were included in this national audit, of whom 546 were undergoing first laser treatment for diabetic maculopathy. The validation exercise would suggest that just over $75 \%$ of all possible eligible patients were recruited into the study. Of the units from which no questionnaires were received, $70.6 \%$ had two or fewer consultant ophthalmologists, and it is possible that many of these small units may not have had any eligible patients during the study period. There appeared to be no differences between those patients missed from inclusion and those included in the audit, and the sample can be thought of as representative. This level of participation compares favourably with the response rate of $66.2 \%$ in the National Cataract Surgery Survey. ${ }^{18}$ The response rates suggest that there was a reduction towards the end of the second month, which was not reflected by a significant increase in the proportion of missed cases. This is probably due to fewer patients undergoing laser treatment during the month of July, which represents the start of the summer holiday period.

The number of patients with maculopathy included in this audit can be extrapolated to represent about 6605 patients annually, which takes into account the level of participation of $75.4 \%$. The 1993 Health Survey for England estimated that there are 1380000 adults with

Table 10. The timing of follow-up $p^{a}$

\begin{tabular}{lrcc}
\hline Weeks & $n$ & $\%$ & Cumulative \% \\
\hline Up to 4 & 43 & 8.7 & 8.7 \\
$5-8$ & 174 & 35.4 & 44.1 \\
$9-12$ & 180 & 36.6 & 80.7 \\
$13-16$ & 61 & 12.4 & 93.1 \\
$>16$ & 34 & 6.9 & 100 \\
Total & 492 & 100 & \\
\hline
\end{tabular}

${ }^{a}$ For those cases whose next appointment was for reassessment rather than specifically for further treatment. diabetes in the UK, ${ }^{1,19}$ and thus it would appear that about $0.48 \%$ of adults with diabetes develop new maculopathy that is detected and treated per annum. The annual incidence of sight-threatening retinopathy amongst diabetics in the UK has been estimated to be $1.2-1.5 \%{ }^{20,21} \mathrm{~A}$ comparison of the number of patients expected to undergo first laser treatment for maculopathy per annum and the numbers actually treated would suggest that there is a significant amount of sight-threatening retinopathy that is not currently being detected or treated in the UK.

\section{Patient characteristics}

Of the patients with maculopathy in this audit, $91.6 \%$ had older-onset diabetes, compared with the fact that $75-90 \%$ of patients with diabetes in the UK are thought to have type 2 diabetes. ${ }^{1}$ Patients with younger-onset diabetes who develop maculopathy are more likely to do so in the presence of proliferative retinopathy than those with older-onset diabetes. ${ }^{3}$ This may explain why there is such a small proportion of patients with younger-onset diabetes in the group of patients with maculopathy discussed in this paper. The mean duration of diagnosed diabetes was lower for the older-onset group than for the younger-onset group. This is in accord with expectations from the WESDR and UK Prospective Diabetes study, ${ }^{22,23}$ and probably reflects the fact that type 2 diabetes may have been present for several years before diagnosis.

\section{Source of referral}

The majority of patients were referred by the hospital physician or their general practitioner. It is probable that the $10.9 \%$ referred by the optometrist is an underestimate, since in the absence of an optometric referral form in the notes, the ophthalmologist completing the questionnaire may not have known whether it was the optometrist or general practitioner who first noted the sight-threatening retinopathy requiring referral. It is of interest to note that the patients themselves stated that it was their optometrist who first told them of the presence of diabetic retinopathy in $26 \%$ of cases. Overall $65.2 \%$ of eyes were identified to have been detected through systematic screening. 


\section{Waiting times}

Whilst the wait for treatment once the diagnosis was made is acceptable ( $93 \%$ being treated within 12 weeks), too high a proportion had an overall wait of more than 12 weeks from referral to treatment, with $35.8 \%$ waiting more than 12 weeks and $17.6 \%$ waiting more than 16 weeks. The wait until the next planned clinic appointment was somewhat variable, but $19.3 \%$ of patients were not seen for more than 12 weeks, with $6.9 \%$ waiting for more than 16 weeks before the next appointment. For eyes with macular oedema and reduced visual acuity this would be undesirable, since repeat treatment is often necessary and should usually be given within 12 weeks.

\section{Visual acuity and type of maculopathy}

About a third of patients ( $31.7 \%$ ) had a visual acuity of $6 / 6$ or better at the time of treatment, which suggests that the disease process was either away from the fovea or the maculopathy was of recent onset. This accords with the finding that $19.4 \%$ of eyes with predominantly exudative maculopathy had exudates that were more than 1 disc diameter from the centre of the macula and that in $15.4 \%$ of eyes the focal/multifocal oedema was more than 1 disc diameter from the centre of the macula. It would therefore appear that some eyes did not have clinically significant macular oedema as defined by the ETDRS. ${ }^{13}$ Interestingly, this group with visual acuity of $6 / 6$ or better waited longer for their initial appointment to be seen in the clinic, probably reflecting prioritisation based on visual acuity.

\section{Treatment given}

The ETDRS recommended focal treatment of microaneurysms and other sites of focal leakage with 50-100 $\mu \mathrm{m}$ spot size burns to obtain definite whitening around the area of leakage. Areas of diffuse leakage within 2 disc diameters of the centre of the macula were treated in a grid fashion using spot sizes of $50-200 \mu \mathrm{m}$. The mechanism of action of macular laser treatment has not been fully elucidated. Although the beneficial effect may be due to direct coagulation of leaking microaneurysms, it is also possible that some effect is due to changes to the retinal pigment epithelium (RPE) and outer retina in both focal and grid treatment. The RPE and outer retina are acutely damaged by laser, and there is evidence that the RPE regenerates and the outer blood-retina barrier is restored. ${ }^{24}$ Destruction of some of the photoreceptors may reduce the metabolic needs of the outer retina, and allows the choriocapillaris to deliver oxygen to the ischaemic inner retina. ${ }^{25}$ It is also possible that grid treatment may stimulate the vascular endothelial repair process and thereby restore the inner blood-retina barrier. ${ }^{26}$ Whatever the basis, the rationale of treatment is largely hypothetical. In this study, the majority of eyes had exudative maculopathy and the majority of these eyes $(96.2 \%)$ had focal treatment. For eyes with diffuse oedematous maculopathy, the majority (78.7\%) were given grid treatment. This is broadly according to expectations based upon the ETDRS regime.

Assuming no distortion of the pattern of practice, an encouragingly high proportion of eyes were treated by consultants. It may be of concern that almost $30 \%$ of patients did not sign a consent form. Although the most important element of a consent procedure is to ensure that the patient understands the nature and purpose of the proposed treatment, it is recommended that written consent should be obtained for any procedure carrying any substantial risk or substantial side-effect. ${ }^{27}$

In conclusion, this audit has provided unique data concerning the process of delivery of photocoagulation treatment for diabetic maculopathy throughout the United Kingdom, and should provide a useful baseline reference for future audits and comparative local and regional audit. Apart from the high percentage of eyes with visual acuity of $6 / 6$ or better, the composition of cases, the retinopathy type and the mode of treatment fall in line with what is expected from the ETDRS. Some shortcomings are the long waiting time from referral to treatment in some cases and the wait until the next appointment after treatment is also unduly long for a significant proportion.

We would like to thank all the ophthalmologists who took part in this audit, and made this study possible. In addition we would like to thank the staff in the clinical audit departments of the units that participated in the validation exercise. We would also like to thank Professor D. McLeod, Mr J. Shilling and Mr J. Talbot for their input on the steering committee for this audit, Professor A. R. Rosenthal as chairman of the audit committee, and the audit secretary Mrs Janice Samson for her efficient assistance.

\section{References}

1. British Diabetic Association Report. Diabetes in the United Kingdom 1996.

2. Klein R, Klein BEK, Moss SE. Visual impairment in diabetes. Ophthalmology 1984;91:1-9.

3. Klein R, Klein BEK, Moss SE, Davis MD, DeMets DL. The Wisconsin Epidemiologic Study of Diabetic Retinopathy. IV. Diabetic macular edema. Ophthalmology 1984;91:1464-74.

4. Sparrow JM, McLeod BK, Smith TD, Birch MK, Rosenthal $A R$. The prevalence of diabetic retinopathy and maculopathy and their risk factors in the non-insulin-treated diabetic patients of an English town. Eye 1993;7:158-63.

5. Grey RHB. The treatment of diabetic maculopathy by argon laser photocoagulation. Trans Ophthalmol Soc UK 1986;105:424-9.

6. Bresnick GH. Diabetic macular edema. Ophthalmology 1986;93:989-97.

7. Kearns M, Hamilton AM, Kohner EM. Excessive permeability in diabetic maculopathy. Br J Ophthalmol 1979;63:489-97.

8. Bresnick GH. Diabetic maculopathy: a critical review highlighting diffuse macular edema. Ophthalmology 1983;90:1301-17.

9. Blankenship GW. Diabetic macular edema and argon laser photocoagulation: a prospective randomised study. Ophthalmology 1979;86:69-78. 
10. Patz A, Schatz H, Berkow JW. Macular edema: an overlooked complication of diabetic retinopathy. Trans Am Acad Ophthalmol Otolaryngol 1973;77:34-42.

11. Townsend C, Bailey J, Kohner E. Xenon arc photocoagulation for the treatment of diabetic maculopathy. Br J Ophthalmol 1980;64:385-91.

12. Olk RJ. Modified grid argon (blue-green) laser photocoagulation for diffuse diabetic macular edema. Ophthalmology 1986;93:938-50.

13. Early Treatment Diabetic Retinopathy Study Research Group. Photocoagulation for diabetic macular edema: ETDRS report no. 1. Arch Ophthalmol 1985;103:1796-806.

14. Early Treatment Diabetic Retinopathy Study Research Group. Photocoagulation for diabetic macular edema: ETDRS report no. 4. Int Ophthalmol Clin 1987;27:265-72.

15. Evans J, Rooney C, Ashwood F, Dattani N, Wormald R. Blindness and partial sight in England and Wales: April 1990-March 1991. Health Trends 1996;28:5-12.

16. Diabetes care and research in Europe: The Saint Vincent Declaration. Diabet Med 1990;7:360.

17. The Diabetes Control and Complications Trial Research Group. The effect of intensive treatment of diabetes on the development and progression of long-term complications in insulin-dependent diabetes mellitus. N Engl J Med 1993;329:977-86.

18. Courtney P. The National Cataract Surgery Survey. I. Method and descriptive features. Eye 1992;6:487-92.
19. Bennett N, Dodd T, Flatley J, Freeth S, Bolling K. Health survey for England 1995. Social Survey Division of the Office of Population Censuses and Surveys, London: HMSO, 1995.

20. Foulds WS, McCuish A, Barrie T, et al. Diabetic retinopathy in the west of Scotland: its detection and prevalence, and the cost-effectiveness of a proposed screening programme. Health Bull 1983;41:318-26.

21. Brunel University Health Economics Research Group. Diabetic retinopathy screening project: Special Medical Development Project Team. Health Economics Research Group report no. 8, 1990.

22. Klein R, Klein BEK, Moss SE, Davis MD, DeMets DL. The Wisconsin Epidemiologic Study of Diabetic Retinopathy. VI Retinal photocoagulation. Ophthalmology 1987;94:747-53.

23. Aldington SJ, Stratton IS, Kohner EM, Matthews DR, Turner RC. Prevalence of retinopathy at diagnosis of type 2 diabetes in the UK prospective diabetes study. Diabet Med 1994;11:S43-4.

24. Wallow IH. Repair of the pigment epithelial barrier following photocoagulation. Arch Ophthalmol 1984;102:126-35.

25. Weiter JJ, Zuckerman R. The influence of the photoreceptor-RPE complex on the inner retina: an explanation for the beneficial effects of photocoagulation. Ophthalmology 1980;87:1133-9.

26. Marshall J, Clover G, Rothery S. Some new findings on retinal irradiation by krypton and argon lasers. Doc Ophthalmol Proc Ser 1984;36:21-37.

27. Department of Health NHS Management Executive. A guide to consent for examination and treatment. 